\title{
MONITORING THE URBAN TREE COVER FOR URBAN ECOSYSTEM SERVICES - THE CASE OF LEIPZIG, GERMANY
}

\author{
E. Banzhaf, H. Kollai \\ Department Urban and Environmental Sociology, Working Group Geomatics \\ UFZ - Helmholtz - Centre for Environmental Research \\ Permoserstr. 15, D-04318 Leipzig \\ Tel. +49-(0)341 - 2351738 \\ Ellen.banzhaf@ufz.de
}

Commission VIII, WG VIII/7 and WG VIII/8

KEY WORDS: Mapping Urban Tree Cover, Urban Ecosystem Functions, Urban Ecosystem Services (urban ESS), Digital Ortho Photos (DOP), Digital Surface Model (DSM), Object-based Image Analysis (OBIA), Inner Urban Differentiation

\begin{abstract}
:
Urban dynamics such as (extreme) growth and shrinkage bring about fundamental challenges for urban land use and related changes. In order to achieve a sustainable urban development, it is crucial to monitor urban green infrastructure at microscale level as it provides various urban ecosystem services in neighbourhoods, supporting quality of life and environmental health. We monitor urban trees by means of a multiple data set to get a detailed knowledge on its distribution and change over a decade for the entire city. We have digital orthophotos, a digital elevation model and a digital surface model. The refined knowledge on the absolute height above ground helps to differentiate tree tops. Grounded on an object-based image analysis scheme a detailed mapping of trees in an urbanized environment is processed. Results show high accuracy of tree detection and avoidance of misclassification due to shadows. The study area is the City of Leipzig, Germany. One of the leading German cities, it is home to contiguous community allotments that characterize the configuration of the city. Leipzig has one of the most well-preserved floodplain forests in Europe.
\end{abstract}

\section{INTRODUCTION}

Simultaneous urban shrinkage and (re)growth have consequences for changes in land use, ecosystem services and related societal impacts. Synergies and trade-offs between land use changes and the provision of urban ecosystem services (UES) as well as the consequences of these interactions for different forms of urban land uses (housing areas, public green spaces, tree coverage etc.) and sociodemographic information need detailed investigations. In order to achieve sustainable urban land use and an appropriate provision of ecosystem services, the monitoring of urban vegetation must be reflected against the background of inner urban differentiation.

Scientific knowledge needs to be produced on land use changes that also include urban tree cover. Urban trees do not only serve as woodland for recreational purpose and nature conservation, they also provide shade in parks and on other green spaces, and thus mitigate urban heat island. Beyond, trees along streets facilitate as a carbon sequestration pool and improve air quality. To estimate the quality of life in different neighbourhoods, tree cover densities help to explain urban areas and their configuration. Beyond, different kinds of vegetation help to explain how the urban fabric is formally organized, how this formal spatial organization characterizes urban neighborhoods in terms of socio-spatial differentiation, and how and which vegetation can contribute to the city in terms of biodiversity. Climate change and urban induced developments from urbanization force science and planners to continuously update their monitoring of the natural environment and to evaluate natural environment.

In Germany, a new kind of administration has been launched under the term of "Doppik" that assigns monetary value to each public property which then provides a nature-based economic mapping of communal assets. As a conclusion, the awareness of trees, bushes and other natural communal assets has been rising, and ecosystem services are being implemented in urban planning.

At an early stage, ecosystem services were explained as “... the conditions and processes through which natural*ecosystems and the species that make them up sustain and fulfil human life" (Daily, 1997: p. 3), followed by the Millennium Ecosystem Assessment (2005) that characterized their four different scopes: provisioning services, regulating services, supporting services and cultural services. Bolund and Hunhammar (1999) emphazise the merit of ecosystem services for urban areas, especially when facing urban environmental challenges evoked by urban growth and climate change (Kabisch, 2015).

\section{STATE OF THE ART}

The role of land use / land cover (LULC) is important to understand the urban ecosystem and to set ecosystems in the context to ecosystem services for urban residents. In the research context of urban greenhouse gas emissions, Baur et al (2015) set the specific focus on spatial structures, but in their study they rather concentrate on urban built-up density 
regarding the urban fabrics than on the vegetation structure and on urban trees as a sequestration source, although urban trees are a spatial determinant for ecosystem services.

Of course, it is important to set the urban fabric in relationship to the urban vegetation pattern to understand urban densification processes and their impact on greenhouse gas emissions. But, in addition, the tree cover, its distribution and development would serve as an essential indicator for this kind of ecosystem service. At a regional scale, Maimaitijiang et al. (2015) discuss the drivers of urban land cover and land use changes by subdividing vegetation cover urban into deciduous and mixed forest, various types of agricultural land, and thus regarding the built-up area in this environmental context to understand urban spatial heterogeneity over time.

In Germany, there is a long-standing research on land-use dynamics at a regional scale, developing new indicators and functionalities (Meinel et al. 2014), and thus providing data of the IÖR-Monitor with an INSPIRE metadata set at Geoportal.de. A newly integrated category is the relief, i.e. the absolute height of a land use above ground, described as indicator relief energy and relief diversity. This indicator pays tribute to the third dimension of land use and land cover for sensible areas such as ecosystems and their services. Furthermore, Walz et al. (2014) incorporates 3D- structural measurements into a raster-based landscape analysis to differentiate landscape structures more appropriately, according to their real-world conditions.

Our approach also makes use of the data set derived from surface models from Airborne Laserscanning (ALS) to get a better picture of vegetation levels, and especially distinguish between young trees and bushes and trees defined as such by their minimum height of 5 meters (EEA convention). As a sophisticated mapping tool, remotely sensed data and techniques serve to differentiate trees from other vegetation structure, as well as from buildings and further anthropogenic elements. Most recently, ALS and LiDAR data are used as ancillary information to identify above-ground LULC elements and distinguish spectrally similar land-use categories by their height information (O’Neil-Dunne et al. 2014). By applying these data sets, the absolute height of single elements is integrated into segmentation processes, following the principles of object-based image analysis, to calculate the delineated segments at a higher differentiation level, and to classify the elements of interest (Rutzinger et al. 2007). Especially for ecosystem management it is understood, that a threedimensional model with fused data from very high resolution imageries and LiDAR data sets are important to reconstruct forest canopies (Chen et al. 2012; Secord and Zakhor, 2007). In this study, we monitor urban trees over a decade to understand their inner urban differentiation and their local contribution to ecosystem services.

\section{STUDY AREA}

Germany does not possess a mega city, but is rather composed of four major cities with more than a million inhabitants (Berlin, Hamburg, Munich, Cologne), and about 15 urban agglomerations with more than 500,000 inhabitants, amongst them is the City of Leipzig (Fig. 1). It is located in East Germany, $180 \mathrm{~km}$ south of Berlin. This city underwent a severe shrinkage phase after reunification in 1990, and is now one of the fastest re-growing cities in Germany. It is composed of large residential areas with Wilhelmenian multi-storey buildings constructed between 1850 and 1915 (more than 22,000 buildings of that type). As one of the East German leading cities it is home to contiguous community allotment as neighbourhood open spaces that characterize the configuration of the city (Table 1).

\begin{tabular}{|l|l|}
\hline Population in 2013 & 531,562 inh. \\
\hline Area in 2013 & $297.38 \mathrm{~km}^{2}$ \\
\hline Population density & $1,787 \mathrm{inh} . / \mathrm{km}^{2}$ \\
\hline Unemployment rate in 2014 & $9.4 \%$ \\
\hline Latitude & $51^{\circ} 19^{\prime} 44^{\prime \prime} \mathrm{N}$ \\
\hline Climate & Transitional Continental \\
\hline Altitude & $113 \mathrm{~m}$ \\
\hline Rainfall & $595 \mathrm{~mm} / \mathrm{a}$ \\
\hline Mean temperature in 2014 & $11.0^{\circ} \mathrm{C}$ \\
\hline Forest area in 2012 & $20.81 \mathrm{~km}^{2}$ \\
\hline Area of public green spaces & $121 \mathrm{~m}^{2}$ per capita \\
\hline Area of community allotments & $8.43 \mathrm{~km}^{2}$ \\
\hline
\end{tabular}

Table 1. Socio-demographic and environmental indicators for the City of Leipzig (Source: City Council of Leipzig)

Leipzig has one of the most well-preserved floodplain forests in Europe that crosses the urbanized area from south to north, and northwest bound, that acts as the green lung of the city. The City Council subdivided the urban area into 10 urban districts which are central planning spaces for urban development. The historical centre is in the middle of the city as central district, surrounded by nine other administrative urban districts (Fig. 1 (c)).

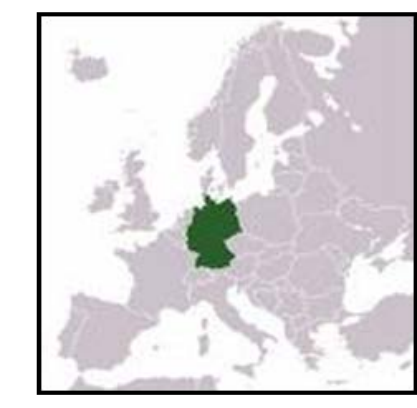

(a)

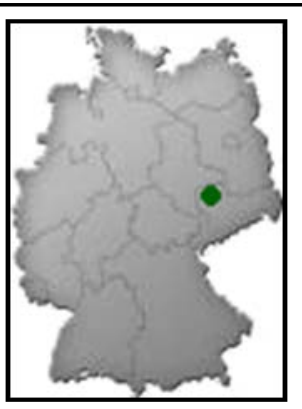

(b)

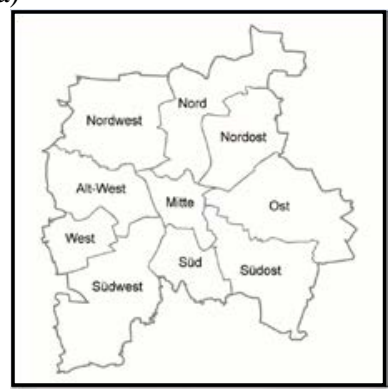

(c)

Figure 1. Location of case study, (a) in Europe, (b) in Germany, (c) City of Leipzig with its 10 urban districts

\section{METHODOLOGY}

We present the update of a monitoring system in which single standing trees and woodland serve as environmental indicator for ecosystem service in the spatial context of urban districts in the City of Leipzig. Therefore urban trees are monitored by 
means of multiple data sets to get a detailed knowledge on its distribution and change over the entire city and its 10 urban districts. The presented study is based on digital orthophotos (DOP) at the spectral resolution of Colorinfrared Imageries (CIR in 2002; RGBI for 2012) that originally possess a ground resolution of $20 \mathrm{~cm}$ for the years 2002 and 2012 .

For the first tree canopy layer the pixel size needed to be comprised to $80 \mathrm{~cm}$ due to data processing limitations. This spatial resolution still served well to distinguish treetops, but additional height information is lacking for this point in time. To some extent, the resampling of DOPs also filtered from heterogeneities (e.g. roof windows) inside objects that where defined previously. In this preprocessing step all DOPs have been mosaicked to cover the whole extent of Leipzig. As the most appropriate processing methodology, we applied the object-based image analysis (OBIA) in eCognition. The segmentation process is explained in detail for the classification in 2012.

For the analysis of 2012 data set, data fusion of very highresolution DOP and LiDAR derivatives (2m DEM, DSM) was feasible in OBIA. Hence, trees can be differentiated from other vegetated areas such as bushes and lawn. Young trees are still hard to be differentiated from bushes due to their similar height. Non-vegetated surfaces can be separated into buildings and other anthropogenic surfaces.

Thresholds of indices and height measures are used to classify the initial objects that are created within the segmentation process. Not part of the presented study is the differentiation of buildings, and only mentioned briefly: the ranges of height serve well to differentiate types of housing as height of buildings is typically similar within a certain era and often distinct between different periods.

The first preprocessing step is alike the one of 2002, i.e. mosaicking and resampling of the DOPs. The normalized difference vegetation index (NDVI) is then calculated from DOP (Fig. 2 (b)). To match pixel size DEM and DSM have been resampled to $80 \mathrm{~cm}$ as well. To receive true objects heights DEM and DSM have been subtracted (DSM-DEM) to create a normalized Digital Surface Model (nDSM). A multi direction Lee filter is applied to reduce local noise while saving edges. Then, NDVI and nDSM image layers are normalized to a value range of 0-255 (8bit). This step seems to be important for the segmentation process to ensure that none of the input data sets is weighted differently because of a different value range. All input data sets were matched to the same georeference system: ETRS89/UTM Zone 33N (EPSG:25833).

In the following, a Multi-Resolution Segmentation (MRS) is generated with the equally weighted bands Red, Green, Blue, Infrared, normalized NDVI, normalized DSM (scale 15, shape 0.2 , compactness 0.3 ). Stepwise, non-vegetated and vegetated classes are differentiated, followed by further subdivision of the vegetated surface. Here, the normalized bands DSM and NDVI are used to segment the vegetated areas by height and vitality. Because of the rather compact shape of trees and small sized elements, the following parameters were set to scale 5 , shape 0.1 , and compactness 0.8 .

The subsequent classification is based on different measures as the mean height of objects and other statistical measures of height as the 25 or $50 \%$ quantile of pixels in the objects. Quantile parameters are introduced to reduce the effects of mismatching object borders between DOP and nDSM that are result of the central camera perspective and different acquisition technologies. Not only the possibly biased mean values are used, but also thresholds of a minimum amount of pixels above a certain height value are set. In the classification process true value NDVI and nDSM layers are utilized.

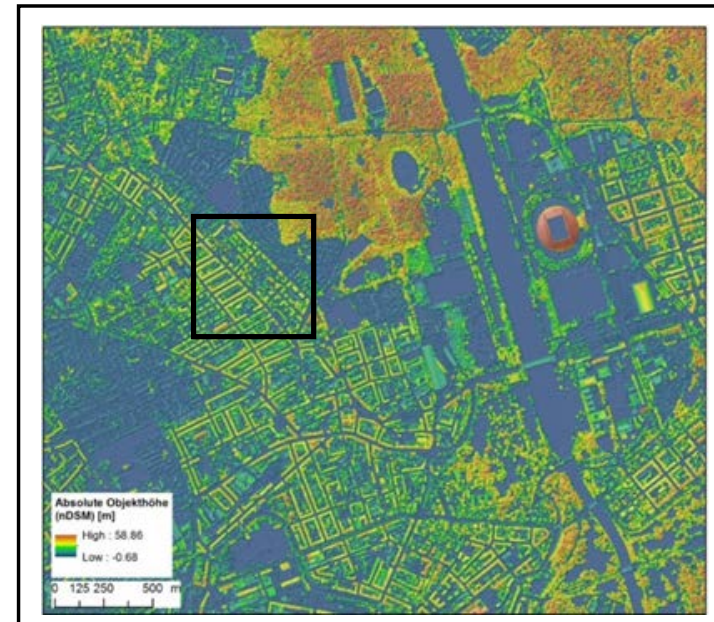

(a)

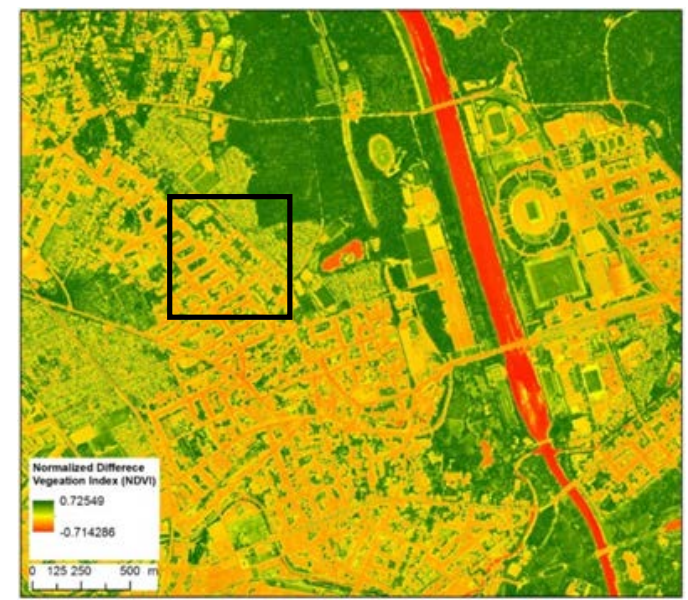

(b)

Figure 2. Display of preprocessed input data (a) the absolute height above ground, (b) the NDVI, both depicting an extraction of the study area: Wilhelmenian style residential buildings (1870-1920) in the west and east, the river "Weiße

Elster" from south to north next to the stadium, and the floodplain forest in the northern part

\section{RESULTS}

As the refined knowledge on the absolute height above ground only exists for the more recent time slot in 2012, it was only then possible to differentiate tree tops from young trees and bushes. So just the general monitoring of the class trees is possible for 2002 and 2012. According to different data sets there is some uncertainty left for the comparison between the two time steps. This is a matter of fact that is inherent in monitoring over time, as methodologies and data quality get continuously enhanced. Visually, both results show high accuracy of tree detection, but only for the year 2012 misclassification due to shadows could be avoided entirely. Fig. 
3 not only presents the distinguished classes of trees, young trees and bushes, as well as lawn and meadows, but also the delineation of residential buildings in a central residential area.

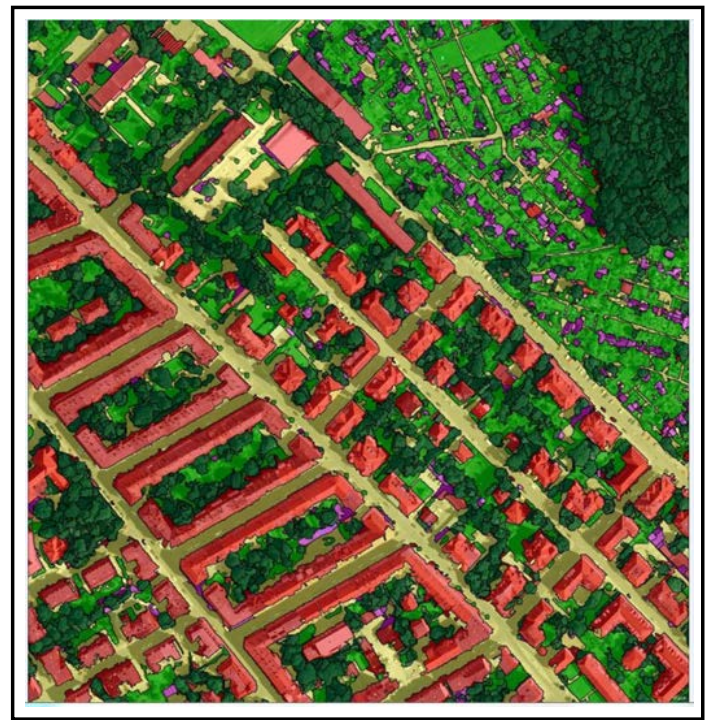

Figure 3. Classified image for a residential area in the City of Leipzig; see square in Fig. 2 for the zoomed-in location

To distinguish the tree cover within the City of Leipzig, the two derived data sets undergo a GIS analysis in which the amount of tree cover is calculated for each urban district. In addition, the differentiation between trees and young trees / bushes is depicted for the year 2012 (Tab. 2).

\begin{tabular}{|l|c|ccc|}
\hline $\begin{array}{c}\text { Urban } \\
\text { district }\end{array}$ & $\begin{array}{c}\text { Trees } \\
\mathbf{2 0 0 2} \\
\text { [ha] } \\
\text { Total }\end{array}$ & Total & $\begin{array}{c}\text { Trees 2012 } \\
\text { [ha] } \\
\text { Young trees } \\
\text { and bushes }\end{array}$ & $\begin{array}{c}\text { Mature } \\
\text { trees }>\text { 5m }\end{array}$ \\
\hline Alt-West & 1001,0 & 1130,9 & 393,9 & 737,0 \\
Mitte & 424,0 & 480,9 & 120,8 & 360,0 \\
Nord & 664,7 & 801,3 & 459,9 & 341,3 \\
Nordost & 687,9 & 825,7 & 458,1 & 367,6 \\
Nordwest & 1038,9 & 1199,9 & 473,9 & 726,0 \\
Ost & 895,7 & 1025,9 & 610,8 & 415,1 \\
Süd & 856,7 & 977,8 & 241,3 & 736,5 \\
Südost & 908,5 & 1011,6 & 472,6 & 539,1 \\
Südwest & 883,0 & 1106,6 & 526,8 & 579,8 \\
West & 421,2 & 534,1 & 299,4 & 234,7 \\
\hline
\end{tabular}

Table 2. Area covered by trees within the urban districts of the City of Leipzig for the years 2002 and 2012. In 2012 a further differentiation is undertaken for mature trees $>5 \mathrm{~m}$, and young trees and bushes

Soon after reunification in 1990, urban environment has got a significant push in urban planning due to shrinkage processes until after the turn of the millennium, and the aim to perform attractively in local neighbourhoods, produce greening on brownfields as an interim use, raise the vegetation connectivity in the city, and rouse the awareness of residents for a green city. In this context, the City Council has promoted a strong campaign for a "Baumstarke Stadt" (in English: trees for a stronger city suggesting environmentally, socially and healthwise) which obviously supports the success of gaining more trees in the different districts. In 2002 the total amount of urban trees was set as 7,781.6 ha, while it rose to 9,094.7 ha in 2012 (summing up the total figures of trees in the respective years, Tab. 2). Hence, in each of the 10 urban districts an increase is observed, some stating a stronger increase than others.

A strikingly higher differentiation can be undertaken for the assignment of young trees and bushes and the mature trees. Young trees and bushes cover a large area and represent planting activities during the last two decades. These figures witness the effort of the City council to develop and strengthen a prosperous environment for Leipzig, enhance the ecosystem services and increase the life quality in neighbourhoods through tree planting. But inherent in the figures of young trees and bushes is also the inaccuracy to which share the green infrastructure is covered by younger trees and by bushes respectively.

\section{CONCLUSIONS}

The urban tree cover is an important piece of information to differentiate types of residential areas, to characterize urban forest, and delineate infrastructural development. It serves as an environmental indicator to understand the impact of land use changes due to the highly dynamic urban re-growth on ecosystem function and the special challenges of urban ecosystem services for human well-being. Critical methodological aspects are that first, in each monitoring sequence over many years the quality and quantity of available input data improves and evokes the ambition to enhance the result. This is a very prosperous procedure for one step in time, but inherently to long-term monitoring, not all distinguished details of the classified results will then remain comparable. Second, the presented methodology defines one single class for young trees and bushes. This is a weakness in the quantitative analysis. It still needs to enhance the differentiation between young trees and bushes, to make a clearer statement on the actual area covered by younger trees only. In this context, LiDAR point clouds could support the subdivision of young trees and bushes and will be tested in our ongoing research.

\section{ACKNOWLEDGEMENTS}

We want to thank the Ordnance Survey of the State of Saxony, Germany for the kind appropriation of the above-mentioned data sets DOP, DEM and DSM (C) Staatsbetrieb Geobasisinformation und Vermessung Sachsen).

\section{REFERENCES}

Baur, A.H., Förster, M., Kleinschmit, B. 2015. The spatial dimension of urban greenhouse gas emissions: analyzing the influence of spatial structures and LULC patterns in European cities. Landscape Ecology, DOI 10.1007/s10980-015-0169-5.

Bolund, P., Hunhammar, S., 1999. Ecosystem services in urban areas. Ecol. Econ. 29, 293-301.

Chen, L.C., Huang, C.Y., and Teo, T.A., 2012. Multi-type change detection of building models by integrating spatial and spectral information, International Journal of Remote Sensing, Vol. 33, No. 6, pp. 1655-1681. (SCI/EI).

Daily, G. (ed.), 1997. Nature’s Services: Societal Dependence of Natural Ecosystems.Island Press, Washington, DC, p. 392. 
European Environmental Agency (EEA). EUNIS categories. Habitat Types Key Navigation. Category: (G) Woodland, forest and other wooded land. http://eunis.eea.europa.eu/habitatskey.jsp?level=2\&idQuestionLink=--\%3E\&pageCode=G; accessed 2015/03/24.

Kabisch, N. 2015. Ecosystem service implementation and governance challenges in urban green space planning - The case of Berlin, Germany. Land Use Policy, 42, 557-567.

Maimaitijiang, M., Ghulam, A., Onésimo Sandoval, J.S. 2015. Drivers of land cover and land use changes in St. Lous metropolitan area over the past 40 years characterized by remote sensing and census population data. Int. Journal of Applied Earth Observation and Geoinformation, 35, 161-174.

Meinel, G., Krüger, T., Schumacher, U., Hennersdorf, J., Förster, J., Köhler, C., Walz, U., Stein, C. 2014. Aktuelle Trends der Flächennutzungsentwicklung, neue Indikatoren und Funktionalitäten des IÖR-Monitors. IÖR-Schriften, 35-43.

Millennium Ecosystem Assessment, 2005. Ecosystems and Human Well-being: Synthesis.

O’Neil-Dunne, MacFaden, S., Royar, A. 2014. A versatile, production-oriented approach to high-resolution tree-canopy mapping in urban and suburban landscapes using GEOBIA and data fusion. Remote Sensing, 6, 12837-12865, doi:10.3390/rs61212837.

Rutzinger, M., Höfle, B. \& Pfeifer, N. (2007): Detection of high urban vegetation with airborne laser scanning data. In: Proceedings forestsat 2007. Montpellier, France, November, 2007., pp. digital media.

Secord, J., Zakhor, A. 2007. Tree detection in urban regions using aerial LiDAR and image data. IEEE Geoscience and Remote Sensing Letters, Vol. 4, No. 2, 196-200. 